\title{
ANALISIS KEBUTUHAN PERANCANGAN ULANG APLIKASI MOBILE TEMAN BUMIL MENGGUNAKAN FRAMEWORK SCRUM
}

\author{
${ }^{1)}$ Meiliani Kuswandi, ${ }^{2)}$ Clara Hetty Primasari*, ${ }^{3)}$ Yohanes Priadi Wibisono, ${ }^{4)}$ Aloysius Bagas \\ Pradipta Irianto \\ 1,2,3,4)Program Studi Sistem Informasi, Fakultas Teknologi Industri, Universitas Atma Jaya Yogyakarta \\ 1,2,3,4) Jl. Babarsari No. 43 Yogyakarta 55281 \\ E-mail : meilianikuswandi@gmail.com, clara.hetty@uajy.ac.id,priadi.wibisono@uajy.ac.id, \\ bagas.pradipta@uajy.ac.id
}

\begin{abstract}
ABSTRAK
Melihat potensi startup healthtech yang terus bermunculan di Indonesia, tentunya perusahaan harus terus menciptakan inovasi untuk tetap dapat bersaing dengan kompetitor yang sudah ada maupun yang akan hadir, salah satunya adalah dengan melakukan revamp atau proses untuk mengubah tampilan dan user journey. Seperti yang dilakukan salah satu perusahaan startup healthtech yakni PT. Global Urban Esensial pada salah satu produknya yaitu aplikasi Teman Bumil. Penelitian ini dilakukan untuk melakukan proses perancangan ulang tampilan dan user journey pada aplikasi Teman Bumil dengan metode perancangan yang digunakan adalah framework Scrum. Tahapan Scrum yang dilakukan yaitu first meeting, sprint planning meeting, sprint, sprint review meeting dan sprint retrospective meeting. Pengumpulan data dilakukan dengan studi dokumentasi, observasi, dan wawancara yang kemudian data tersebut dianalisis menggunakan model Miles dan Huberman dengan tahapan reduksi data, penyajian data, dan kesimpulan. Melalui penelitian ini diketahui bahwa perancangan ulang dilakukan untuk mengubah tampilan dan memperbaiki experience dengan mempersingkat flow penggunaan aplikasi, serta proses dokumentasi perancangan aplikasi menggunakan panduan product requirements document yang terdiri dari tiga bagian utama, yaitu user requirements, halaman antarmuka, dan flowchart.
\end{abstract}

Kata Kunci: Perancangan Ulang; Scrum; Teman Bumil; startup; healthtech

\begin{abstract}
Seeing the potential for healthtech startups that continue to emerge in Indonesia, of course companies must continue to create innovations to be able to compete with existing and future competitors, one of which is by doing a revamp or a process to change the appearance and user journey. As was done by one of the healthtech startup companies, namely PT. Global Urban Essentials in one of its products, namely the Teman Bumil application. This research was conducted to redesign the display and user journey in the Teman pregnant woman application. The design method used was the Scrum framework. The Scrum stages carried out are the first meeting, sprint planning meeting, sprint, sprint review meeting and sprint retrospective meeting. Data collection was carried out by studying documentation, observation, and interviews. Then the data were analyzed using the Miles and Huberman model with the stages of data reduction, data presentation, and conclusions. Through this research, it is known that the redesign was carried out to change the appearance and improve the experience by shortening the flow of application use, as well as the application design documentation process using the product requirements document guide which consists of three main parts, namely user requirements, interface pages, and flowcharts.
\end{abstract}

Keyword: Revamp; Scrum, Teman Bumil; startup; healthtech

\section{PENDAHULUAN}

Indonesia merupakan salah satu negara Asia yang menunjukan pertumbuhan layanan kesehatan digital. Seperti pada Gambar 1. yang menyatakan bahwa dalam riset yang dilakukan oleh Galen Growth Asia menunjukkan bahwa ekosistem layanan kesehatan berbasis digital di Indonesia sebesar 5\% dan memiliki peluang untuk semakin berkembang melihat inovasi lokal yang mulai bermunculan. Meskipun persebaran layanan kesehatan belum optimal, akan tetapi hal ini memberikan potensi pada kesehatan berbasis digital untuk dapat berbaur dengan industri lainnya [1]. 


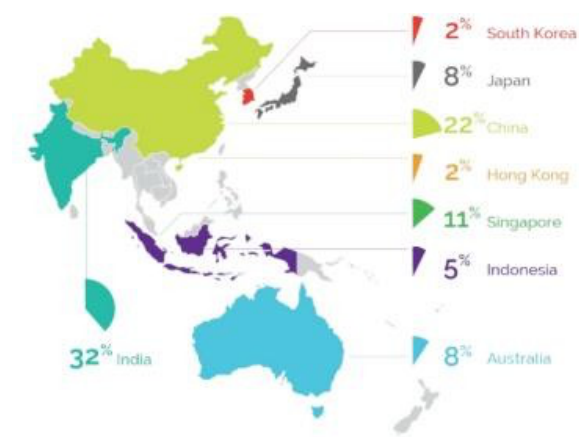

Ekosistem layanan healthtech di negara Asia / Galen Growth Asia

Gambar 1. Ekosistem Layanan Healthtech

Pada era yang serba digital, informasi apapun khususnya yang berkaitan dengan kesehatan dapat ditemukan hanya dengan mengakses melalui internet. Masyarakat dapat menemukan informasi kesehatan dengan mengetik kata kunci, sehingga tidak perlu datang dan menunggu antrian untuk konsultasi tatap muka dengan dokter, hingga mengeluarkan biaya yang dapat dibilang mahal [2]. Melalui survei APJII yang ditunjukkan melalui Gambar 2. menjelaskan bahwa sebesar $51,06 \%$ internet dimanfaatkan untuk mencari informasi kesehatan dan $14,05 \%$ untuk berkonsultasi dengan dokter [3]. Dengan survei ini, dapat dijadikan sebagai salah satu peluang untuk ekosistem kesehatan digital berkembang di Indonesia.

Dikarenakan potensi startup healthtech yang terus bermunculan [4], maka tentunya perusahaan harus terus menciptakan inovasi untuk tetap dapat bersaing dengan kompetitor yang sudah ada maupun yang akan hadir [5], karena hakekatnya inovasi dan persaingan merupakan dua hal yang tidak dapat dipisahkan. Dengan adanya persaingan maka perusahaan memiliki motivasi untuk berinovasi, dan inovasi akan membuat persaingan menjadi lebih menarik [6]. Inovasi merupakan sebuah bentuk gagasan yang kemudian diimplementasikan sehingga dapat diterima sebagai sebuah hal baru [7]. Selain itu, inovasi juga adalah salah satu aspek yang penting dalam perusahaan startup. Sebuah inovasi dapat membantu perusahaan dalam menciptakan ide baru, proses baru, hingga terciptanya produk baru yang berkualitas untuk memberikan keunggulan bagi perusahaan dalam persaingan [6][7].

Salah satu inovasi yang perusahaan dapat lakukan adalah dengan revamp atau proses yang dilakukan untuk merancang ulang aplikasi [8]. Dalam melakukan revamp diharapkan dapat mewujudkan tampilan dan experience yang sesuai dengan kebutuhan end-user, karena user interface merupakan hal yang pertama kali akan dilihat oleh pengguna dan tampilan yang bagus harus diseimbangkan dengan kemudahan dalam penggunaannya [7][9]. Akan tetapi tampilan aplikasi Teman Bumil pada versi sekarang sudah tidak cocok untuk tren sekarang dan juga banyaknya flow yang tidak dibutuhkan lagi. Sehingga penelitian ini bertujuan untuk melakukan proses perancangan ulang tampilan dan user journey aplikasi Teman Bumil sehingga diharapkan penelitian ini dapat membantu perusahaan agar proses perancangan ulang dapat lebih efektif dan efisien, serta membantu peneliti selanjutnya untuk memahami proses perancangan ulang aplikasi.

\section{METODE}

Metode yang digunakan pada penelitian ini adalah metode penelitian kualitatif. Sugiyono (2020) memberikan pengertian mengenai penelitian kualitatif yaitu penelitian dilakukan dengan analisis dan interpretasi teks untuk menemukan makna dari sebuah fenomena [10]. Samiaji (2017) menyebutkan bahwa penelitian ini mencoba untuk memahami fenomena tanpa berusaha memanipulasi fenomena yang sedang diamati [11]. Teknik analisis data yang digunakan pada penelitian ini adalah analisis kualitatif model Miles dan 
Huberman. Terdapat tiga ktivitas pada analisis data kualitatif, yaitu reduksi data, penyajian data, dan kesimpulan [10].

\section{A. Reduksi data}

Reduksi data diartikan merangkum, memilih, dan menentukan kondisi pokok yang telah didapatkan dari observasi dan wawancara [12], sehingga data yang telah direduksi kemudian menghasilkan gambaran yang lebih jelas dan mempermudah peneliti untuk melanjutkan melakukan pengumpulan data [10].

B. Penyajian Data

Data yang telah direduksi selanjutnya akan disajikan dengan singkat dan jelas dalan memahami permasalahan yang diteliti [12]. Menurut Miles dan Huberman dalam buku Sugiyono menyebutkan bahwa bentuk penyajian data yang paling sering digunakan adalah teks yang bersifat naratif [10].

\section{Kesimpulan}

Langkah terakhir yang dilakukan pada tahap analisis adalah menarik kesimpulan yang dalam penelitian kualitatif, kesimpulan merupakan temuan baru yang belum pernah ada dan dapat berbentuk deskripsi ataupun gambaran obyek yang sebelumnya masih belum jelas [12].

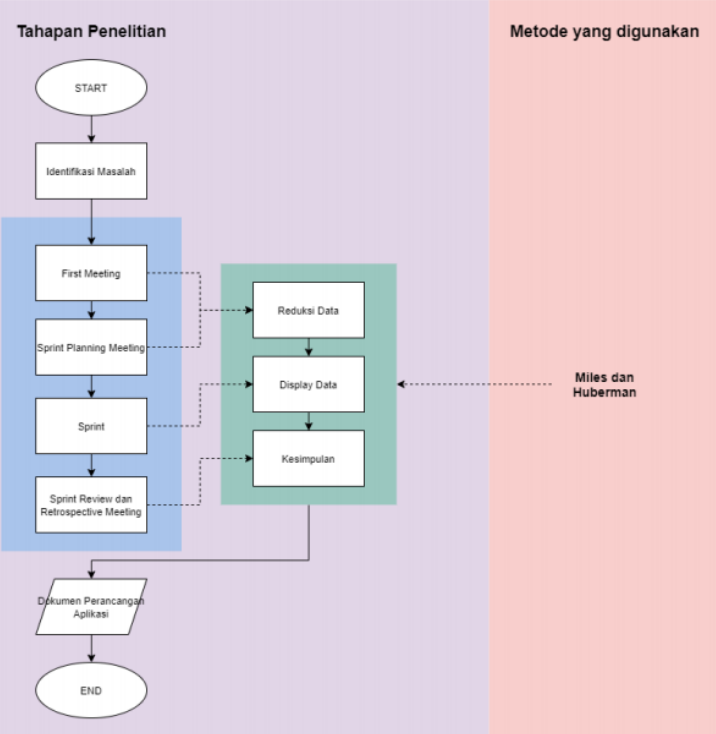

Gambar 4. Kerangka Kerja Penelitian
Proses perancangan ulang dalam penelitian ini dilakukan dengan metode Scrum yang merupakan kerangka kerja yang digunakan untuk menyelesaikan permasalahan, mengembangkan, dan mengelola sebuah produk yang kompleks. Gambar 3. adalah fase Scrum yang menurut pencipta Scrum, Ken Schwaber dan Jeff Sutherland terdiri dari 5, yaitu [13]:

\section{SCRUM FRAMEWORK}

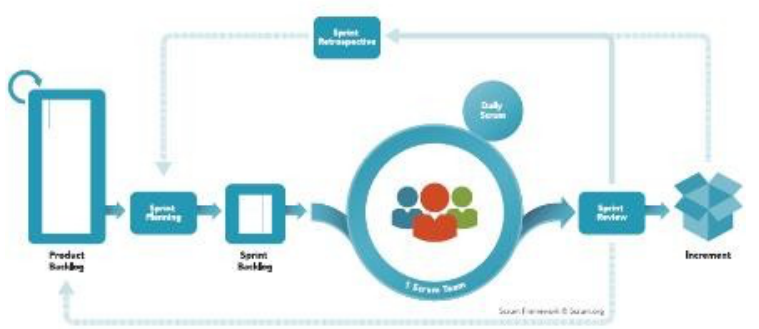

Gambar 3. Framework Scrum

\section{A. First Meeting}

First meeting adalah kegiatan untuk membuat product backlog. Product backlog adalah daftar kebutuhan pada aplikasi dan sumber syarat dalam merancang aplikasi [14]. Backlog dibuat secara urut berdasarkan skala prioritas, namun backlog harus selalu diperkirakan kembali. Sehingga dengan kata lain backlog dapat berubah dalam perjalan sprint [15].

\section{B. Sprint Planning Meeting}

Sprint planning meeting adalah pertemuan pertama untuk mengawali sprint. Dalam pertemuan ini kegiatan yang dilakukan adalah merencanakan durasi Scrum yang biasanya dilaksanakan selama 10 hari kerja. Pada kegiatan ini timmemecah product backlog ke dalam sprint backlog untuk menentukan berapa banyak task yang akan dikerjakan selama sprint [13]. 


\section{Daily Scrum Meeting}

Daily scrum meeting atau bisa juga disebut daily stand up meeting merupakan pertemuan yang dilakukan setiap hari selama sprint berjalan dan berdurasi kurang lebih 15 menit agar tim dapat mengetahui perkembangan terbaru dalam sprint dan menjelaskan kegiatan yang akan dilakukan pada hari itu [14][16]. Untuk mengurangi kompleksitas, daily scrum meeting dilakukan pada waktu dan tempat yang sama dengan hari sebelumnya [16].

\section{Sprint Review Meeting}

Pertemuan sprint review meeting dilakukan setelah aktivitas selama sprint berakhir. Dilakukan untuk meninjau kembali pencapaian

\section{HASIL}

\section{A. First Meeting}

First meeting dilakukan untuk berdiskusi bersama membahas kegiatan yang akan dilakukan pada Teman Bumil untuk menentukan tujuan, lama pengerjaan, memikirkan risiko, dan strategi. Sehingga dari hasil first meeting didapati bahwa aplikasi Teman Bumil akan dirancang ulang. Selain itu kegiatan ini juga dilakukan untuk membuat product backlog untuk mengetahui fitur yang diprioritaskan dalam kegiatan akan dirancang ulang pada fase pertama seperti pada Gambar 5.

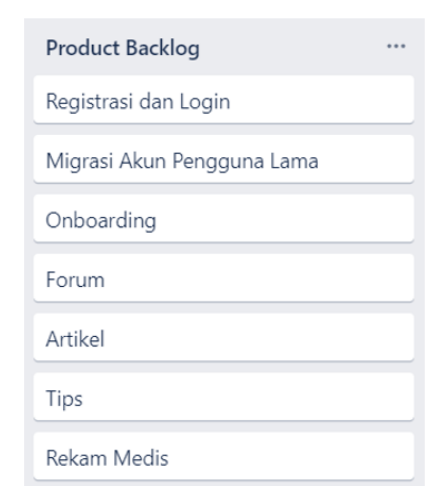

Gambar 5. Product Backlog Menggunakan Trello yang telah diraih. Dalam pertemuan ini juga product backlog akan ditinjau apakah memerlukan perubahan prioritas [16].

\section{E. Sprint Retrospective Meeting}

Pertemuan ini merupakan kesempatan bagi scrum team untuk mengkaji diri sendiri dan membuat perencanaan yang berhubungan untuk meningkatkan pada sprint berikutnya. Sprint retrospective dilakukan setelah sprint review dan sebelum sprint planning berikutnya [16]. Diakhir pertemuan, scrum team diminta untuk menyepakati satu perbaikan kecil agar semakin baik pada sprint berikutnya [15].

\section{B. Sprint Planning Meeting}

Sprint planning meeting adalah kegiatan yang dilakukan setiap kali mengawali fase sprint untuk menentukan target kegiatan selama dua minggu ke depan. Selain target, pembahasan lainnya adalah mengenai pembagian tugas setiap individu.

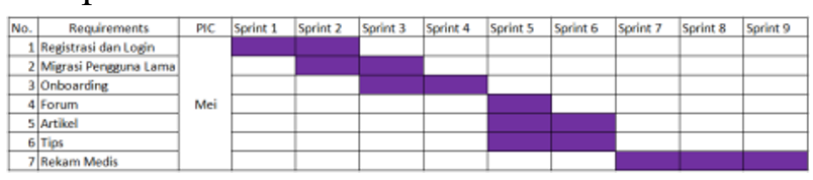

Gambar 6. Sprint Backlog

\section{Sprint}

Sebelumnya proses registrasi aplikasi Teman Bumil menggunakan email. Pada perancangan ulang ini proses registrasi akan diubah menggunakan nomor ponsel. Sehingga pada sprint 1 dan 2 kegiatan yang dilakukan adalah merancang proses registrasi menggunakan nomor ponsel. Hasil sprint 1 dan 2 ditunjukkan melalui gambar $7-9$ yang adalah tampilan registrasi menggunakan nomor ponsel dari aplikasi Teman Bumil.

Pada Gambar 7 pengguna diminta untuk menambahkan nomor ponsel dan dilanjutkan dengan verifikasi nomor ponsel 
menggunakan One Time Password (OTP) pada Gambar 10.

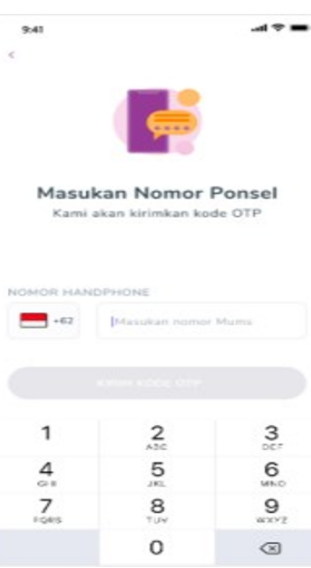

Gambar 7. Tampilan Halaman Menambahkan kode OTP

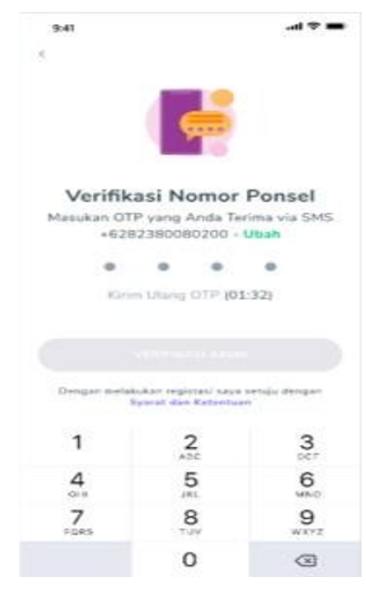

Gambar 8. Tampilan Halaman Menambahkan kode OTP

Pada Gambar 8 pengguna akan menambahkan kode OTP yang sebelumnya telah dikirimkan melalui pesan singkat. Pada tampilan ini pengguna dapat mengubah nomor ponselnya dan meminta pengiriman kembali kode OTP. Kemudian pengguna akan diminta untuk menambahkan nama lengkap seperti pada Gambar 9.

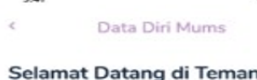

Bumil!
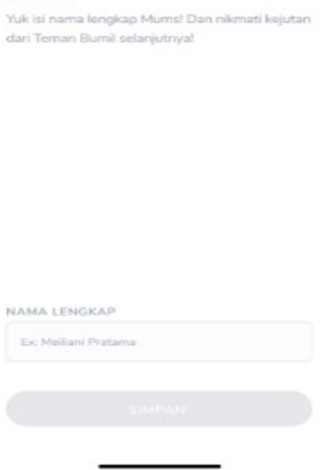

Gambar 8. Tampilan Pengisian Nama

Lengkap

Pada proses registrasi, data diri yang diminta hanyalah nama lengkap, kemudian pengguna dapat melengkapi data diri ketika sudah masuk ke dalam aplikasi. Mengingat terjadi perubahan cara dalam melakukan registrasi, maka penting untuk mendeteksi perangkat yang pengguna miliki untuk menemukan data akun sebelumnya jika pengguna telah memiliki akun. Maka hasil pengerjaan saat sprint 3 dapat dilihat pada gambar $10 \quad-13$ yang merupakan tampilan jika ditemukan data sebelumnya pada perangkat tersebut.

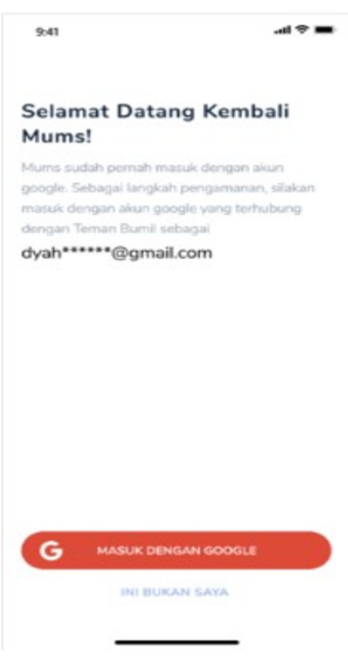

Gambar 10. Tampilan Halaman Menemukan Data Google 


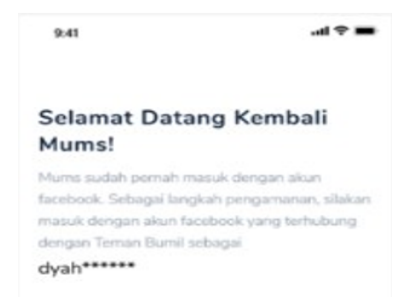

Gambar 11. Tampilan Halaman Menemukan Data Facebook
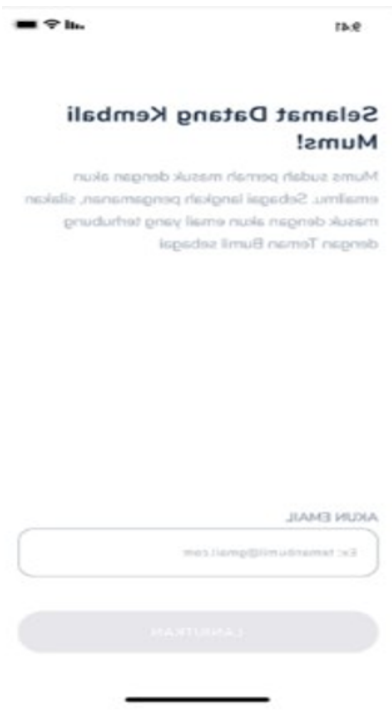

Gambar 12. Tampilan Halaman Menemukan Data Email

Terdapat 3 cara untuk menautkan kembali akun pengguna, yaitu menggunakan Google,

\section{KESIMPULAN}

Dari hasil dan pembahasan maka dapat disimpulkan bahwa perancangan ulang dilakukan untuk memberikan penyegaran untuk pengguna agar tidak merasa bosan sekaligus memperbaiki journey dengan mempersingkat flow penggunaan aplikasi.
Facebook, atau email. Akan tetapi jika akun tersebut bukanlah milik pengguna maka pengguna dapat memilih opsi "bukan saya" dan akan dialihkan pada Gambar 13.
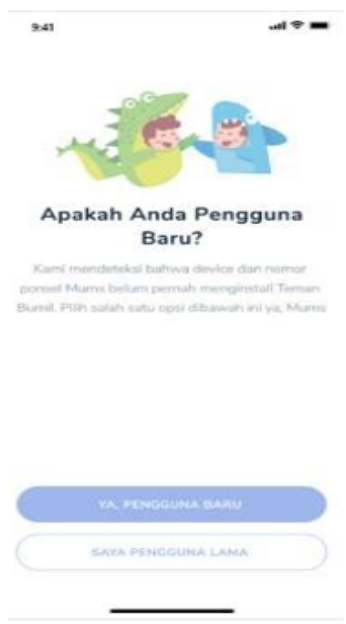

Gambar 13. Tampilan Halaman Pengguna Lama

Gambar 13 adalah tampilan halaman yang akan tampil jika pengguna memilih opsi "bukan saya". Terdapat dua pilihan opsi pada halaman ini, yaitu pengguna baru dan pengguna lama. Jika pengguna memilih opsi pengguna lama, maka pengguna akan diminta untuk melakukan login dengan tiga pilihan, yaitu menggunakan Google, Facebook, atau email. Pada sprint 3 dilakukan juga perubahan pada proses onboarding yang hanya akan dilalui oleh pengguna baru. Terdapat tiga pilihan program yang dapat dipilih, yaitu program promil (program hamil), program kehamilan, dan program tumbuh kembang anak.

Perubahan yang terjadi pada aplikasi Teman Bumil adalah user interface dan user experience sesuai dengan hasil evaluasi user journey. Perubahan cara registrasi yang sebelumnya menggunakan email ini didasari karena nomor ponsel dianggap data yang sulit untuk didapatkan sehingga menjadikan data nomor ponsel berharga. Mengingat terjadi perubahan dalam proses registrasi, maka 
penting bagi perusahaan untuk melakukan migrasi akun pengguna lama agar data pengguna lama tidak hilang saat melakukan verifikasi nomor ponsel. Oleh sebab itu maka perusahaan akan mendeteksi perangkat untuk menemukan akun pengguna yang ada pada perangkat tersebut. Onboarding yang hanya dilalui oleh pengguna baru juga akan diubah dengan mempersingkat flow onboarding untuk memberikan kesan kepada pengguna seperti tidak sedang berada di proses onboarding.

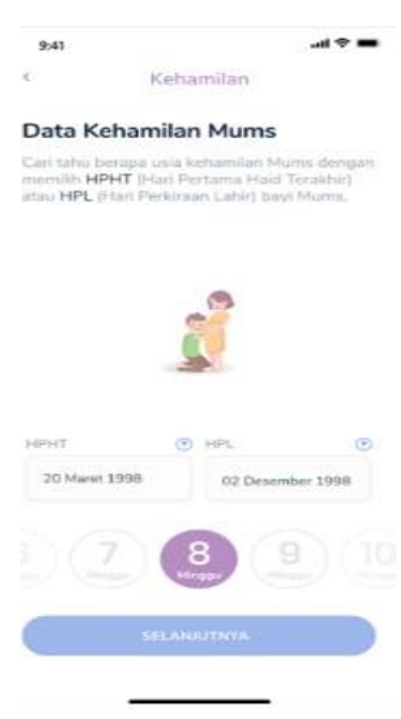

Gambar 14. Tampilan Halaman Onboarding Kehamilan

Gambar 14 adalah tampilan halaman onboarding program kehamilan. Pengguna akan diminta untuk menambahkan tanggal Hari Pertama Haid Terakhir (HPHT) atau tanggal Perkiraan Lahir (HPL). Tersedia juga slider mingguan apabila pengguna hanya mengetahui usia kehamilannya.

\section{Sprint Review dan Retrospective Meeting}

Setelah sprint berakhir, dilakukan sprint review dan retrospective meeting untuk melihat kembali hasil pengerjaan selama sprint berjalan. Setelah dilakukan sprint review dan retrospective meeting didapatkan hasil bahwa flow registrasi diharapkan seminimal mungkin untuk menghindari flow yang tidak berguna dan kalimat di setiap program onboarding dibuat asertif untuk menyemangati pengguna.

\section{DAFTAR PUSTAKA}

[1] Y. Yenny, "Layanan Healthtech di Asia Berkembang Pesat, di Indonesia Belum Signifikan," 2018. [Online]. Available:

https://dailysocial.id/post/healthtechdi-asia.

R. Dewi, P. A. Janitra, and N. Aristi, "Pemanfaatan Internet Sebagai Sumber Informasi Kesehatan Bagi Masyarakat MKK: Volume 1 No 2 November 2018 MKK: Volume 1 No 2 November 2018," vol. 1, no. 2, pp. 162-172.

[3] Indonesian Internet Service Provider Association, "Penetrasi dan Perilaku Pengguna Internet Indonesia," Apjii, 2017.

[4] Kersa, "Melirik' Trend Startup Di 2020." [Online]. Available: https://cubic.id/journals/meliriktrend- startup-di-2020.

[5] F. D. P. Sari and S. N. B. Sitepu, "Peran Faktor Internal dan Faktor Eksternal pada Keberlangsungan Start-Up Bisnis Kota Surabaya," $J$. Manaj. Teor. dan Terap., vol. 9, no. 1, pp. 12-22, 2016, doi: http://dx.doi.org/10.20473/jmtt.v9i1. 2783.

[6] R. A. Wijaya, N. Ilhama, and B. Paramastri, "Pentingnya Pengelolaan Inovasi Dalam Era Persaingan," vol. 5, no. 2, pp. 217-227, 2019.

[7] E. Fitriyadi, "Masyarakat Industri 4 . 0," J. Teknol. dan Inf. ESIT, vol. XIV, 
no. 11, pp. 34-39, 2019.

[8] P. Harian, "Revamp \& Refactor, apasih definisinya bagi programmer?," 2019. [Online]. Available:

https://medium.com/@harianprogram mer/revamp- refactor-apasihdefinisinya-bagi-programmer5e381a160315.

[9] M. G. Hartadi, I. W. Swandi, and I. W. Mudra, "Warna Dan Prinsip Desain User Interface (Ui) Dalam Aplikasi Seluler 'Bukaloka," J. Dimens. DKV Seni Rupa dan Desain, vol. 5, no. 1, p. 105, 2020, doi: 10.25105/jdd.v5i1.6865.

[10] P. D. Sugiyono, Metode Penelitian Kualitatif. Bandung: Penerbit Alfabeta, 2020.

[11] P. Samiaji Sarosa, S.E., M.Info.Sys., Penelitian Kualitatif Dasar-Dasar, 2nd ed. Jakarta: Penerbit Indeks, 2017.

[12] A. Ufie, "Kearifan Lokal (local Wisdom) Budaya Ain Ni Ain Masyarakat Kei Sebagai Sumber Belajar Sejarah Lokal Untuk Memperkokoh Kohesi Sosial Siswa," Repository.Upi.Edu, pp. 39-55, 2011.

[13] N. S. Sibarani et al., "Metode Scrum," Imp. J. Interdiscip. Res., vol. 2, no. 12, pp. 293-298, 2017.

[14] M. A. Firdaus, "Implementasi Kerangka Kerja Scrum Sistem Informasi," Semin. Nas. Teknol. Inf. dan Multimed. 2017, vol. 1, no. 2, pp. 283-288, 2017.

[15] J. Sutherland, SCRUM Meningkatkan Produktivitas Dua Kali Lipat dalam Waktu Setengahnya Saja. Yogyakarta:
Penerbit Bentang, 2017.

[16] M. C. Layton and D. Morrow, Scrum 2nd Edition. 